\title{
Phosphorylation-Regulated Cell Surface Expression of Membrane Proteins
}

\author{
Yukari Okamoto and Sojin Shikano \\ University of Illinois at Chicago, \\ USA
}

\section{Introduction}

To maintain its functional integrity, a cell senses and reacts to the acute or chronic changes in the environment under physiological and pathological conditions. This typically involves cell surface membrane proteins such as receptors, ion channels, and structural proteins, whose surface expression level is regulated at multiple different steps of their biosynthesis and trafficking. Protein trafficking is mediated by a series of dynamic interactions between the sorting motifs of cargo proteins and the cellular machineries that recognize these motifs. While the constitutive trafficking of many cargo proteins relies on intrinsic sorting signals, post-translational modification of cargo proteins often serves as a key switch that enables the spatio-temporal regulation of their trafficking. Protein phosphorylation is one of the most intensively studied post-translational modifications that control the membrane trafficking. However, molecular mechanisms by which phosphorylation signal regulates the protein localization are diverse and remain not fully understood. The 14-3-3 proteins had been identified to specifically recognize phosphorylated serine or threonine residues, and thus represents one of the most distinct effector molecules that function downstream of the phosphorylation signal by kinases. This chapter will focus on the emerging role of 14-3-3 proteins in the phosphorylation-dependent control of cell surface membrane protein trafficking.

\section{Control of cell surface expression by phosphorylation signal}

A typical mechanism by which phosphorylation signal controls protein trafficking is that phosphorylation of cargo proteins creates docking sites for the interacting proteins. A well studied example is the internalization of G protein-coupled receptors (GPCRs), where ligand binding induces the conformational change of the receptor and subsequent recruitment of GPCR kinases (GRKs) to the receptor. Receptor phosphorylation by GRKs recruits arrestin that couples the receptor to the adaptor protein of clathrin coat, thereby initiating the internalization of the cargo vesicles (Drake et al., 2006; Tobin, 2008). This way phosphorylation signal leads to the desensitization of ligand stimulus by reducing the cell surface density of GPCRs. On the other hand, phosphorylation signalling can also regulate localization of membrane proteins by attenuating the sorting signal activity. In the neuron, ligand stimulation of N-methyl-D-aspartate (NMDA) receptor leads to receptor phosphorylation by casein kinase II (CK2) at the serine residue within the C-terminal PDZ 
[postsynaptic density-95 (PSD-95)/Discs large/zona occludens-1] binding motif (IESDV$\mathrm{COOH}$ ) of NMDA receptor subunit 2B (NR2B). CK2 phosphorylation disrupts the interaction of NR2B with the PDZ domains of PSD-95 and SAP102 and thereby decreases cell surface NR2B expression (Chung et al., 2004). This represents the regulatory role of phosphorylation in excitatory synaptic function and plasticity.

In contrast to the downregulation of surface expression, the molecular basis for the role of phosphorylation in promoting cell surface trafficking has been less well understood. However, studies in the past decade have revealed that 14-3-3s are the key class of phosphosensing proteins which mediate cell surface trafficking of various membrane proteins. Here we will review recent findings on the emerging role of 14-3-3 in cell surface protein trafficking, with particular focus on their mechanisms of action and relevant kinases.

\subsection{4-3-3 proteins and 14-3-3 binding sites}

The 14-3-3 proteins were first discovered in 1967 as brain-rich, acidic protein (Moore \& Perez, 1967). The name 14-3-3 refers to the elution and migration profile of these proteins on DEAEcellulose chromatography and starch gel electrophoresis. They are highly conserved and expressed in all eukaryotic cells, with seven isoforms in mammals $(\beta, \gamma, \varepsilon, \zeta, \eta, \tau, \sigma)$ and two in yeast (Bmh1 and Bmh2). 14-3-3 proteins participate in fundamental biological processes such as signal transduction, metabolism, protein degradation, and trafficking (Tzivion \& Avruch, 2002; van Hemert et al., 2001). All the 14-3-3 proteins, except for the sigma isoform, are able to form stable homo- and heterodimers (Benzinger et al., 2005; Gardino et al., 2006; Wilker et al., 2005). The dimeric structure of the 14-3-3 protein allows it to simultaneously bind two binding sites through an amphipathic ligand-binding groove present in each monomer. In the majority of cases, 14-3-3 proteins recognize phosphorylated peptides in their binding partners. Screening of phosphoserine-oriented peptide libraries has identified two consensus 14-3-3 binding motifs that are present in many of known 14-3-3 binding proteins (Yaffe et al., 1997). These are R-[S/ $\phi]-X-p S / p T-X-P$ (mode I) and R-X-[S/ $\phi]-X-p S / p T-X-P$ (mode II) binding sites where $\mathrm{pS} / \mathrm{pT}$ is phosphoserine or phosphothreonine, $\phi$ is an aromatic residue, and $X$ is any residue (typically leucine, glutamate, alanine, and methionine). However, it should be noted that 14-3-3-binding sites in numerous proteins do not conform to these optimal motifs, presumably because other structural features also contribute to the interactions. For instance, proline located at position +2 of the phosphorylation site occurs in only about half of known 14-3-3 binding motifs in mammalian proteins (Johnson et al., 2010).

The C-terminal 14-3-3 binding motifs have recently become a newly recognized group with a distinct mode of interaction (see Table 1). Based on the similarity between the C-terminal 14-3-3 binding motifs of the oAANAT (RRNpSDR-COOH) and $\mathrm{H}^{+}$-ATPase (QQXYpTV$\mathrm{COOH})$ proteins, a new mode III consensus for 14-3-3 binding $\left(\mathrm{pSX}_{1-2}-\mathrm{COOH}\right)$ had been proposed (Ganguly et al., 2005). The focal points of this consensus are that the motif is at the extreme C-terminus in contrast to the canonical mode I and II internal binding sites, and that the binding is phosphorylation-dependent. Mode III sequences interact with the same ligand-binding groove of 14-3-3 as do the mode I and mode II motifs (Coblitz et al., 2005). Amino acid selectivity upstream of the phosphorylated residue is conspicuously absent from the proposed mode III motif, presumably due to the discrepancy between the oAANAT and $\mathrm{H}^{+}$-ATPase motifs. However, upstream arginine residues are preferred for modes I and II 14-3-3 binding as determined by random synthetic peptide library screening 


$$
\begin{aligned}
-\mathrm{R}-\mathrm{S} / \phi-\mathrm{X}-\underline{\mathrm{S}} / \underline{\mathrm{T}}-\mathrm{X}-\mathrm{P}- & \text { Model } 14-3-3 \text { binding } \\
-\mathrm{R}-\mathrm{X}-\mathrm{S} / \phi-\mathrm{X}-\underline{\mathrm{S}} / \underline{\mathrm{T}}-\mathrm{X}-\mathrm{P}- & \text { Modell } 14-3-3 \text { binding }
\end{aligned}
$$

\begin{tabular}{rlc} 
& Reported Mode III 14-3-3 binding proteins & Reference \\
SIRYSGHSL-COOH & Ib $\alpha$ of Ib-IX-V complex & 1 \\
MSKARSWTE-COOH & IL-9R $\alpha$ receptor & 2 \\
RRSSV-COOH & TASK-1 channel & 3 \\
RRKSV-COOH & TASK-3 channel & 4 \\
RGRSWTY-COOH & RGRSWTY & 5 \\
RKRSVSL-COOH & GPR15 receptor & 6 \\
SYRSSTL-COOH & HAP1A & 7 \\
QQSYTV-COOH & Plant plasma membrane H+-ATPase & 8 \\
RRNSDR-COOH & AANAT acetyltransferase & 9 \\
RRRQT-COOH & p27Kip1 cyclin kinase inhibitor & 10 \\
\hline
\end{tabular}

Table 1. 14-3-3 binding sequences. Consensus mode I and mode II motifs and the reported C-terminal mode III binding sequences are shown. $\underline{\text { }} / \underline{T}$ : phosphorylated serine or threonine required for 14-3-3 binding, $\phi$ : aromatic residue, Reference\#1: (Bodnar et al., 1999) , \#2: (Sliva et al., 2000), \#3 and \#4: (O'Kelly et al., 2002):, \#5 and \#6: (Shikano et al., 2005), \#7:(Rong et al., 2007), \#8: (Wurtele et al., 2003), \#9: (Ganguly et al., 2005), \#10: (Fujita et al., 2003).

(Yaffe et al., 1997) and by random C-terminal peptide selection in a cell-based genetic screen (Shikano et al., 2005). Indeed, the majority of the so far identified C-terminal 14-3-3 binding sequences contain arginine residues upstream of the phosphorylated serine or threonine (Table 1). Recent mutagenesis study of the C-terminal 14-3-3 binding site in GPR15 demonstrated the importance of the upstream arginine residue for phosphorylationdependent 14-3-3 binding (Okamoto \& Shikano, 2011). In a crystal structure with 14-3-3, a mode II peptide displayed an arginine in the -4 position from phosphorylated serine (RLYHpSLPA) that was looped back to interact with the phosphate on the peptide (Rittinger et al., 1999). These lines of evidence support significant contribution of upstream arginine residues to the 14-3-3 affinity. Thus, Mode III would be better defined as RXXpS/pTX$\mathrm{COOH}$. For all three modes of 14-3-3 binding, phosphorylation is a prerequisite and arginine residues located upstream of the phospho-serine/threonine are also important for recognition by a number of kinases (Kobe et al., 2005). Thus, the absence of an arginine residue in the C-terminal 14-3-3 binding sequence in plant $\mathrm{H}^{+}$-ATPase (QQXYpTV-COOH) suggests the possibility that plant and animal differ significantly in kinase recognition. As more C-terminal 14-3-3 binding proteins become available, it would be valuable to revisit the issue of upstream sequence requirements both in terms of 14-3-3 binding per se and in terms of kinase recognition.

\subsection{Protein kinases that phosphorylate 14-3-3 target sites}

Proteomic screens have identified over 200 phosphoproteins which interact with 14-3-3 (Chang et al., 2009; Ichimura et al., 2002; Kakiuchi et al., 2007; Meek et al., 2004; Pozuelo Rubio et al., 2004). Understanding when and how 14-3-3 proteins impact on these targets 
offers a great opportunity to gain mechanistic insights into many phosphorylation-regulated biological pathways. Since 14-3-3 target sites in proteins must satisfy the specificity requirements for both 14-3-3s and the protein kinases that create the sites in the first place, identification of kinases that phosphorylate 14-3-3 target sites is crucial for elucidating the physiological roles of 14-3-3 binding. Unfortunately, in the majority of cases the identity of the physiologically relevant kinases that phosphorylate the mode I, II or III 14-3-3 binding motifs is still unknown. This is largely due to the high similarities between different serine/threonine protein kinase recognition sites (Table 2) and their likely redundant activities. One reasonable approach to overcome such obstacles and gain better understanding of the physiological kinases for 14-3-3 target proteins would be the global analysis of the actual 14-3-3-binding phosphoproteins. Based on the proteomics data and other available literature on 14-3-3, Johnson et al. have recently attempted to define 14-3-3 specificity and identify relevant protein kinases (Johnson et al., 2010). This study points out several features that are distinctive of 14-3-3-binding sequences as compared with other protein phosphorylation sites. For instance, few reported 14-3-3-binding sites have a +1 (relative to phosphorylated serine/threonine) proline residue, which contrasts with phosphoproteomic studies of cell lysates and subcellular fractions where phosphoserineproline is the most commonly reported phosphorylation motif overall (Ubersax \& Ferrell, 2007). This indicates that proline-directed kinases do not phosphorylate 14-3-3-binding sites. Similarly, no reported 14-3-3-binding sites conform to the canonical consensus site for casein kinase II (pS/pT-X-X-D/S/pS), which is probably the second most common type of motif in the entire mammalian phosphoproteome (Salvi et al., 2009). Another interesting notion is that, while the optimal mode I (R-[S/ $\phi]-X-p S / p T-X-P)$ and mode II (R-X-[S/ $\phi]-X-p S / p T-X-P)$ 14-3-3-binding motifs were defined using phosphopeptides, many 14-3-3-binding sites in mammalian proteins (but not in plant 14-3-3-binding proteins) have basic residues in position -5 (and -4 ) in addition to -3 . This creates a motif RXRXXS/T, which is a good target for the basophilic AGC kinase family (cAMP-dependent protein kinases A, cGMPdependent protein kinases $\mathrm{G}$, and phospholipid-dependent protein kinases) and the calcium/calmodulin-dependent kinase (CaMK) family (Pearson \& Kemp, 1991). Indeed, members of these kinase families, including protein kinase A (PKA), protein kinase C (PKC), CaMKI, checkpoint kinases 1 and 2 (Chk1 and 2), Akt/protein kinase B (PKB) and p90 ribosomal S6 kinase (p90Rsk), are all known to phosphorylate sites that mediate 14-3-3 binding (Dougherty \& Morrison, 2004). Among these, Akt is one of the most well documented kinases in phosphorylating 14-3-3 client proteins (Mackintosh, 2004).

\begin{tabular}{cl}
\hline$R-X-R-X-X-S$ & Akt/PKB \\
$R-X-R-X-X-\underline{S}$ & SGK \\
$R-X-R-X-X-\underline{S}$ & S6 kinase \\
K/R-X-X-S & PKA \\
K/R-X-X-S-X-K/R & PKC \\
{$[$ MVLIE] $-\mathrm{X}-\mathrm{R}-\mathrm{X}-\mathrm{X}-\underline{\mathrm{S}}-\mathrm{X}-\mathrm{X}-\mathrm{X}-[\mathrm{MVLIF}]$} & CaMK1 \\
$\mathrm{R}-\mathrm{X}-\mathrm{X}-\underline{\mathrm{S}}$ & $\mathrm{CaMK2}$ \\
\hline
\end{tabular}

Table 2. Consensus recognition sequences of major serine/threonine kinases that are known to phosphorylate 14-3-3 binding site. 


\subsection{Molecular mechanism for the 14-3-3 effects on membrane protein trafficking}

The phospho-binding ability of 14-3-3 proteins is reminiscent of other proteins carrying specific modules that recognize phosphorylated sites. Such modules include FHA (Durocher et al., 2000), WD40 (Yaffe \& Elia, 2001), Polo-box (Lowery et al., 2005), and BRCT (BRCA-1 Cterminal) repeat domains (Manke et al., 2003), which target serine and threonine phosphorylation, as well as SH2 (Src-homology 2) domains which target phosphorylated tyrosine residues in specific sequence contexts (Bradshaw \& Waksman, 2002). These domains are found in a large number of proteins involved in a wide range of signaling processes. 14-3-3s are distinct from those proteins in that 14-3-3s are not modular components of other proteins. They are discrete binding proteins with no intrinsic enzyme activities, except for the nucleoside diphosphate (NDP) kinase-like activity (Yano et al., 1997) and chaperonic activity toward selected substrates (Yano et al., 2006). So, how do 14-33s exert their effects? Several excellent reviews discuss different models of 14-3-3 action as masking, scaffolding, or clamping of proteins (Dougherty \& Morrison, 2004; Mackintosh, 2004; Mrowiec \& Schwappach, 2006). Recruitment of proteins may be regulated by masking of functional signals by 14-3-3 binding. Alternatively, the scaffolding model suggests that 14-3-3 proteins tether different molecules together and form a platform for complex assembly. Clamping describes the idea that 14-3-3 binding alters the functional property of the client protein by stabilizing a certain conformation (Figure 1). It should be noted that combinations of these 'masking', 'scaffolding', and 'clamping' types of 14-3-3 action may occur together. As far as membrane proteins are concerned, very few examples exist where the interactions of 14-3-3 with client proteins are sufficiently well understood to ascribe a particular mode of action. Nevertheless, 14-3-3s may be considered as general switch proteins, of which effect of binding depends on the client protein. In most cases, phosphorylation at a serine or threonine residue activates the switch, and the subsequent binding of 14-3-3 proteins is thought to prevent rapid dephosphorylation. Recent studies have firmly demonstrated that 14-3-3 proteins are involved in controlling cell surface expression level of various cargo membrane proteins. We will discuss the pertinent evidence and hypothetical molecular mechanisms explaining these observations, with attention to the relevant kinases that regulate 14-3-3 binding.

\subsubsection{Masking}

14-3-3s are implicated in regulating the subcellular localization of many phosphorylated target proteins. The majority of the cases seem to involve the mechanism where 14-3-3 binding blocks the access of other proteins to the sorting signal of target proteins. Such a 'masking' role of 14-3-3 was first implicated in the mitochondria-cytoplasm translocation of the pro-apoptotic protein BAD. BAD interferes with the anti-apoptotic function of Bcl-2 and $\mathrm{Bcl}-\mathrm{x}_{\mathrm{L}}$ in the mitochondria by binding to those proteins via its $\mathrm{BH} 3$ domain (Zha et al., 1996). $\mathrm{BH} 3$ domain is located immediately adjacent to the serine ${ }^{136}$, of which phosphoryaltion by Akt (Datta et al., 1997) is required for the binding of BAD to 14-3-3 in the cytoplasm (Zha et al., 1997). These results suggested that 14-3-3 binding obscures the BH3 domain and prevents the targeting of BAD to mitochondria. A similar mechanism was found for the nuclear-cytoplasmic shuttling of various proteins including tyrosine phosphatase Cdc25C (Kumagai \& Dunphy, 1999), transcription factor FKHRL1 (Brunet et al., 1999), glucocorticoidreceptor (Kino et al., 2003), CDK (cyclin-dependent kinase) inhibitor p27 
(A) Masking

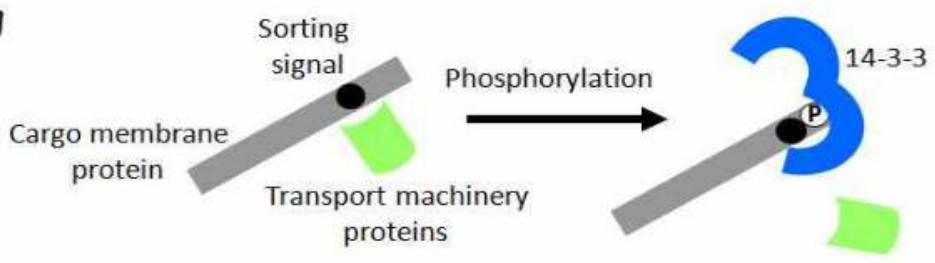

(B) Scaffolding

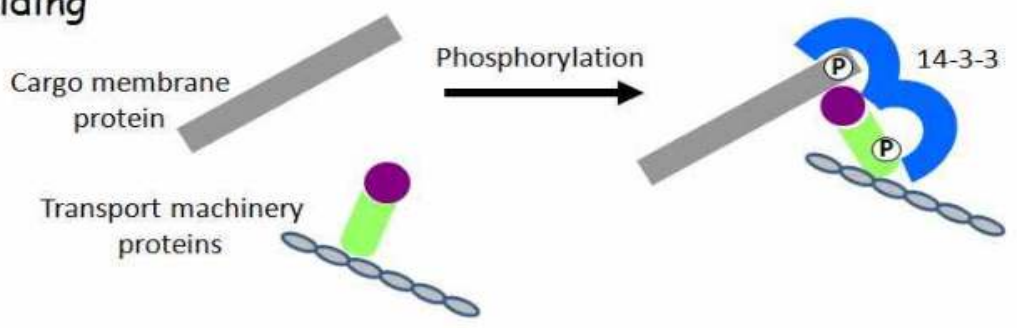

\section{(C) Clamping}

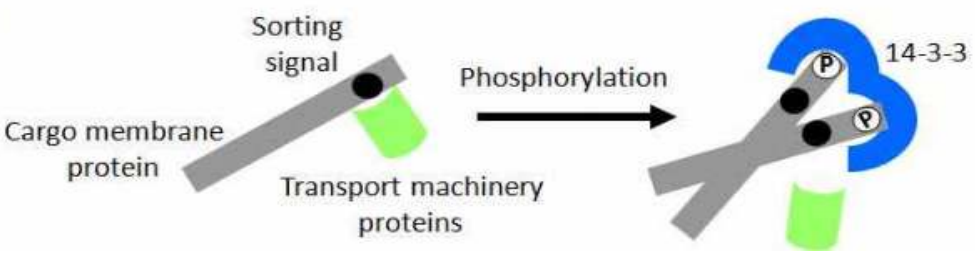

Fig. 1. Hypothetical models for the effects of 14-3-3 binding on the trafficking of membrane proteins. (A) Masking. Sorting signals (e.g., RXR motif) are physically masked by 14-3-3 binding to the nearby phosphorylated target site (shown as B). This blocks the access of transport machineries (e.g., COPI proteins) to the sorting signal. Only the action of one 14-33 monomer is drawn here. (B) Scaffolding. Dimeric 14-3-3 facilitates the interaction of cargo proteins with transport machineries (e.g., motor proteins and microtubules). Binding of 143-3 dimer to two different targets might involve phosphorylation-independent and/or outer surface-mediated interaction (see main text). (C) Clamping. Binding of a 14-3-3 dimer induces a conformation that is unfavorable for sorting signals (e.g., RXR motif), which can be achieved by clustering of targets or relocation from active zones (e.g., proximity to the transmembrane region (see main text)). This could result in reduced accessibility by transport machineries (e.g., COPI proteins).

(Fujita et al., 2003), and catalytic subunit of telomerase TERT (Seimiya et al., 2000). In most cases, 14-3-3 binding promotes the cytoplasmic localization of target proteins. For instance, 14-3-3 binding to serine 287 of Cdc25C leads to the cytoplasmic retention of Cdc25C. This seems to be due to the occlusion of the closely located bipartite nuclear localization sequence (NLS) at amino acids 298-316 of Cdc25C from importin- $\alpha$, a receptor for bipartite NLS (Kumagai \& Dunphy, 1999). These observations are consistent with the predominant cytoplasmic localization of 14-3-3 proteins at the steady-state, which has led to the hypothesis that they might serve as a universal cytoplasmic anchor that blocks import into 
the nucleus or other organelles. However, this model of 14-3-3 action is contradicted by the observation that 14-3-3 can also promote the nuclear localization of other binding partners. Seimiya et al. found that 14-3-3 binding to human TERT, which requires threonine1030, serine ${ }^{1037}$ and serine ${ }^{1041}$, lead to the nuclear localization of hTERT. This was attributed to the blocking of the nearby leucine-rich nuclear export sequence (NES) present at residues 970981 of hTERT, which is otherwise recognized by the nuclear export receptor CRM1 (Seimiya et al., 2000). So, how does 14-3-3 regulate nuclear-cytoplasmic shuttling of different proteins in two opposing directions? One simple hypothesis may be that 14-3-3 itself bears no specific information about protein sorting and the effect of 14-3-3 binding on the subcellular localization of a client protein depends entirely on sorting signals encoded within the client protein and the proximity of those signals to a 14-3-3 binding motif. If so, 14-3-3 binding could possibly affect any other protein sorting pathways.

Consistent with this idea, recent studies report a critical role of 14-3-3 in controlling the cell surface expression level of membrane proteins of different functions, including ion channels, receptors, and adhesion molecules. In many cases, the underlying mechanism seems to involve 'masking' of a short sequence motif, namely a di-arginine or di-basic (RXR) ER localization signal. The RXR-type ER-localisation signals were first identified in ATPsensitive potassium channels (K $\mathrm{K}_{\mathrm{ATP}}$ channels) (Zerangue et al., 1999). These channels assemble as octameric complexes consisting of four Kir6 channel subunits and four sulphonylurea receptor (SUR) subunits, and each of these subunits carries an RXR signal in the cytoplasmic tail. It is believed that the ER-localisation activity of these motifs is mediated by the retrieval of cargo proteins from the post-ER compartments such as ER-Golgi intermediate compartment (ERGIC) and cis-Glogi through their interaction with the retrograde transport coatomer protein, COPI (Michelsen et al., 2007; Zerangue et al., 1999). Although the RXR motif resembles the C-terminal di-lysine (KKXX) motif which also mediates ER retrieval of membrane protein cargos through direct interaction with COPI (Michelsen et al., 2007), RXR motif is distinct in that it is present almost exclusively in the multimeric cell surface membrane proteins (Michelsen et al., 2005), while KKXX motif is found in the membrane proteins that are resident to the ER such as nucleotide sugar transporters (Jackson et al., 1990, 1993).

Efficient cell surface transport of proteins harbouring RXR motifs will be allowed only when the motif becomes inaccessible to COPI probably by multiple different mechanisms including folding, subunit assembly, post-translational modification, and protein recruitment. 14-3-3 proteins have been implicated in the masking of RXR motif in several instances. The first evidence that 14-3-3 proteins control cell surface transport of membrane protein was shown for two-pore-domain potassium $\left(\mathrm{K}_{2 \mathrm{P}}\right)$ channels TASK1 and TASK3 (O'Kelly et al., 2002). These channels bound to 14-3-3 via a mode III C-terminal binding motif (RRSSV-COOH and RRKSV-COOH for TASK1 and TASK3, respectively), where phosphorylation of the penultimate serine and the upstream arginine residues were critically required. In the absence of phosphorylation on the penultimate serine, COPI proteins bind to the adjacent RXR-like sequence (KRR) which shares two arginine residues with the 14-3-3 binding motif. It is thought that phosphorylation switch allows 14-3-3 binding that occludes the partially overlapping RXR-like COPI binding motif. A very recent study by Mant et al. reports that PKA, which recognizes a consensus sequence of RXXS/T, phosphorylates the penultimate serine residue in TASK1 and TASK3 channels and promote their expression on cell surface, 
although it was not shown in the literature whether this phosphorylation actually promotes the binding of 14-3-3 proteins to these sites (Mant et al., 2011).

A similar masking mechanism was suggested for the ER-export of Iip35 isoform of major histocompatibility complex (MHC) class-II-associated invariant chain (O'Kelly et al., 2002). During their assembly in the ER, MHC class-II $\alpha \beta$ dimers associate with preformed trimers of the invariant chains (Iip33, Iip35, Iip41, Iip43), to form nonameric (aßIi) 3 oligomers. It had been known that phosphorylation of an N-terminal serine ${ }^{8}$, present exclusively in the Iip35 cytoplasmic tail ( $\left.\mathrm{NH}_{3}-\mathrm{MHRRRSRS} . ..\right)$, is a prerequisite for efficient ER exit and sorting of class-II/Iip35 complexes to the cell surface. Phosphorylation of serine ${ }^{8}$ leads to the 14-3-3 binding to Iip35 and the alanine mutation on this residue inhibits the ER exit of classII/Iip35 complex (Kuwana et al., 1998). Together with the fact that 14-3-3 and COPI bound to the N-terminal sequence of Iip35 in a mutually exclusive manner, it was concluded that the cell surface transport of MHC class-II complex is promoted by 'masking' effect of 14-3-3 (O'Kelly et al., 2002). However, as Khalil et al. pointed out (Khalil et al., 2005), this model seems to require further investigation, since it is not consistent with the fact that, even when associated with a 14-3-3 protein, Iip35 will not leave the ER in the absence of class-II molecules and that mutation of serine ${ }^{8}$ to asparagine prevents 14-3-3 protein binding but still allows ER export if class-II molecules are present (Kuwana et al., 1998).

The effect of 14-3-3 binding on promoting cell surface transport was also found by a completely different approach. Shikano et al. screened a random peptide library to identify C-terminal peptide signals that would functionally override the ER localization activity of the RXR motif (Shikano et al., 2005). The screening was based on the yeast growth complementation assay using a mutant Saccharomyces cerevisiae SGY1528 which cannot survive in low potassium media due to the lack of endogenous potassium uptake transporters. However, SGY1528 growth in low potassium media can be rescued by heterologous expression of mammalian inward rectifying potassium channel Kir2.1, but not when Kir2.1 was artificially fused with the RXR motif (RKR) due to the efficient retention of channel in the ER (Shikano et al., 2005). In the screen, SGY1528 cells were transformed with Kir2.1 constructs where random peptide library of 8-mer sequences was placed at the extreme C-terminus, downstream of the implanted RXR motif. By selecting the transformed cells that survived in low potassium media, the authors searched for the sequence that were able to override the ER localization activity of the RXR motif and restored the surface expression of the chimeric Kir2.1 channel. The screen of about $2 \times 10^{6}$ clones yielded several sequences that showed robust surface expression of Kir2.1 as tested in mammalian cell. Those sequences shared a minimum consensus of RXXS/TX-COOH and showed strong binding to 14-3-3, which required penultimate serine or threonine and the upstream arginine residues (Shikano et al., 2005). By using one of the identified C-terminal sequences, namely RGRSWTY-COOH, Chung et al. investigated the relevant kinases. Using in vitro phosphorylation assay using recombinant proteins and in vivo studies using reporter Kir2.1 channel bearing both RXR motif and downstream C-terminal RGRSWTY sequence, the authors found that Akt, but not PKA or CamKII, is responsible for direct phosphorylation of the RGRSWTY sequence which recruits 14-3-3 proteins to this site (Chung et al., 2009). Importantly, the extracellular stimulation that activates Akt pathway, such as insulin and platelet-derived growth factor (PDGF), enhanced 14-3-3 binding and promoted the cell surface transport of the reporter Kir2.1 channel (Chung et al., 2009). These results 
demonstrate that, despite high similarity in the recognition sequences of basophilic serine/threonine protein kinases, specific kinase signaling can modulate membrane protein trafficking through 14-3-3 binding. Further search of the human protein database for this Cterminal 14-3-3-binding motif has identified several candidate membrane proteins that would interact with 14-3-3. These include GPR15, an orphan GPCR that serves for a coreceptor for human immunodeficiency virus (HIV) entry (Farzan et al., 1997). GPR15, which has a C-terminal sequence of RRRKRSVSL-COOH, was indeed confirmed to bind 14-3-3 and this binding absolutely required phosphorylation of penultimate serine ${ }^{359}$. A recent study by Okamoto and Shikano reported that alanine mutation of the serine ${ }^{359}$ resulted in substantial ER localization of GPR15 and this was mediated by the upstream arginine residues at amino acids 352 and 354, which constitute a COPI-binding RXR motif (Okamoto \& Shikano, 2011). These results suggested that mode III binding of 14-3-3 to the receptor C-terminus physically occludes the adjacent RXR motif from the access by COPI, similar to the cases for TASK channels. Thus, a non-biased screening has led to the identification of 14-3-3 function as a key switch that converts phosphorylation signal to the sorting of membrane proteins by modulating the activity of an ER localization signal.

The masking effect of 14-3-3 on the cell surface transport is not restricted to the mode III Cterminal binding. The cytoplasmic tail of ADAM22, a member of ADAM (a disintegrin and metalloprotease domain) protein family, contains two internal 14-3-3 binding sites and three RXR-type ER-localization signals that overlap with both of the 14-3-3 protein binding sites. Mutations in both 14-3-3 binding sites inhibited surface expression of ADAM22, while deletion of both RXR motif and 14-3-3 binding sites restored the surface expression (Godde et al., 2006). Although this study did not investigate COPI interaction with ADAM22, the results suggest the possibility that 14-3-3 binding inhibited the COPI-dependent ER localization activity of RXR signal.

The cell surface transport of a gap junction protein connexin 43 is also promoted by 14-3-3 binding to its internal mode I binding site (RASSRP) (Park et al., 2007). The authors have found that Akt phosphorylates the serine ${ }^{373}$ in this site in the epidermal growth factor (EGF)stimulated cell. Although not characterized yet, the existence of an overlapping RXR motif (RPR) suggests a possible masking effect of 14-3-3 on the cell surface transport of connexin 43.

NMDA receptors are tetramers composed of homologous subunits (NR1; NR2A-D; NR3A-B (Cull-Candy \& Leszkiewicz, 2004). There are multiple NR2 subunits, each with unique spatio-temporal expression patterns, ensuring functional diversity of NMDA receptors. Recently, cerebellar NR2C subunit was found to be directly phosphorylated by Akt at the sequence that conforms to mode I 14-3-3 binding motif (RPRHASLP) (Chen \& Roche, 2009). The Akt phosphorylation induced by insulin growth factor (IGF-1) results in the recruitment of 14-3-3 and the increase of cell surface expression of NMDA receptors. Although the causative role of 14-3-3 in surface transport remains unclear in this study, the presence of ER localization signals (Horak \& Wenthold, 2009) in the NR1 subunit and the obligatory assembly of NR2 with NR1 for functional NMDA receptor suggest a possible mechanism where Akt-induced 14-3-3 binding to NR2C attenuates the activity of ER localization signals in NR1 by physically occluding them.

Interestingly, 14-3-3s have also been reported to bind directly to the RXR motif itself in a phosphorylation-independent manner. By using an artificial multimer of the distal C- 
terminus of Kir6.2 channel in pull-down assays from cytosolic cellular extracts, Yuan et al. showed that 14-3-3 proteins preferentially bound to the RXR motif (RSRR) in the oligomerized form (Yuan et al., 2003). This interaction was sufficient to allow the exit of a multimeric reporter protein carrying this motif from the ER and promote the subsequent transport to the cell surface. Although the precise role of the 14-3-3 binding in the cell surface transport of octameric $\mathrm{K}_{\mathrm{ATP}}$ channel consisting of four Kir6.2 and four SUR1 seems to require further investigation (Heusser et al., 2006), this study demonstrated the possibility that 14-3-3 serves for a constitutive check point of ER protein quality control which ensures the cell surface delivery of functional multimeric membrane proteins by preferentially inactivating the ER localisation signals on the properly oligomerized subunits.

\subsubsection{Scaffolding}

The stable dimeric structure immediately suggests that 14-3-3s might serve as a simple 'scaffold', where two different target proteins bind simultaneously to each monomer of the same 14-3-3 dimer. Indeed, 14-3-3 proteins are often referred to as 'scaffolding proteins' in the literature. However, while 14-3-3s are components of multiprotein complexes (Munday et al., 2000; Pnueli et al., 2001; Widen et al., 2000), the evidence showing the 14-3-3 dimers acting as an intermolecular bridge between two different substrates had been limited to several earlier studies including those reporting the pairings involving Raf-1, namely Raf-1 and Bcr (B-cell receptor) (Braselmann \& McCormick, 1995), Raf-1 and A20 (Vincenz \& Dixit, 1996) and Raf-1 and PKC了 (Van Der Hoeven et al., 2000). Nevertheless, in the context of membrane protein trafficking, some recent studies implicate the scaffolding role of 14-3-3 in promoting the cell surface expression of membrane proteins.

14-3-3 promotes the ER export of $\mathrm{N}$-cadherin through coupling the $\mathrm{N}$-cadherin/ $\beta$-catenin/PXRICS complex to the microtubule-based motor proteins dynein/dynactin (Nakamura et al., 2010). 14-3-3 $\zeta$ or 14-3-30 directly interacts in a phosphorylation-dependent manner with a mode I site (RSKSDP) of PX-RICS, a $\beta$-catenin-interacting GTPase-activating protein for Cdc42, and this seems to facilitate ER to Golgi trafficking by association of $N$-cadherin/ $\beta$ catenin cargo with minus-end motor proteins dynein/dynactin. This results in the increased localization of $\mathrm{N}$-cadherin/ $\beta$-catenin at cell-cell contact sites. The authors have also shown that CaMKII is responsible for direct phosphorylation of PX-RICS and the subsequent 14-3-3 binding by using in vitro phosphorylation assay and siRNA knockdown of CaMKII (Nakamura et al., 2010). It is of note that a similar scaffolding function has been reported for a PDZ protein that couples a cargo receptor and a motor protein which mediates microtubule-based trafficking. PDZ domain of mLin-10 directly interacts with the Cterminal PDZ-binding motif of a neuron-specific plus-end molecular motor KIF-17. mLin-10 also forms a complex with its family members mLin-2 and mLin-7, which in turn interact with PDZ-binding motif of NMDA receptor subunit 2B (Setou et al., 2000).

The interactions between the a3 subunit of the nicotinic acetylcholine receptor (nAChR) and a multi-subunit cytoskeletal-anchoring complex provide another evidence suggesting possible scaffolding role of 14-3-3 (Rosenberg et al., 2008). APC (adenomatous polyposis coli) organizes a multi-protein postsynaptic complex that targets a $3 \mathrm{nAChRs}$ to synapses. APC interaction with the microtubule plus-end binding protein EB1 is essential for a3nAChR surface membrane insertion and stabilization. 14-3-3 directly interacts with a3 subunit in a phosphorylation-dependent manner and also forms complex with APC. Thus, 14-3-3 
proteins may provide for a mechanism by which nAChRs containing only specific subunits are recruited to postsynaptic clusters and may stabilise them there. In both of the above studies, it is still not clear whether and how a 14-3-3 dimer binds to two separate targets with each monomer. Multiple proteomic screenings have revealed that 14-3-3s form complex with a large number of proteins closely involved in vesicular trafficking such as motor proteins, coat proteins, and GTPase regulators (Mrowiec \& Schwappach, 2006). Therefore it is conceivable that 14-3-3 proteins do modulate membrane trafficking by serving as a scaffold that connects cargo proteins with cellular transport machineries.

Then, does a 14-3-3 dimer really bind to two different proteins at the same time? It seems somewhat unlikely that there would be frequent occasions where a 14-3-3 dimer binds two separate targets via each canonical ligand-binding groove, unless those target proteins happen to be already close enough to each other and in such position that both of their phosphorylated binding sites can be accommodated by the binding grooves of the same 143-3 dimer, whose core is a rigid and unyielding structure (Obsil et al., 2001), but not by the neighboring 14-3-3 dimers. Crystal structure of 14-3-3 $\zeta$ : AANAT revealed that in addition to the phosphorylation-dependent interaction through its canonical ligand-binding groove, 143-3 also makes extensive contacts with AANAT via other regions of the 14-3-3 channel, although these contacts must be insufficient to form a stable complex (Obsil et al., 2001). Moreover, a recent finding by Barry et al. demonstrated that 14-3-3 can directly interact with other proteins outside of the canonical binding groove, providing a possible molecular basis for the scaffolding function of 14-3-3 (Barry et al., 2009). 14-3-3 $\zeta$ undergoes phosphorylation at tyrosine ${ }^{179}$ upon cytokine stimulation and this leads to the binding of Shc protein through its $\mathrm{SH} 2$ domain that recognizes phosphorylated tyrosine. This 14-3-3/Shc complex is required for the recruitment of a phosphatidylinositol 3-kinase (PI3K) signaling complex and the regulation of cell survival in response to cytokine. Although this study did not describe whether Shc-bound 14-3-3 proteins bind to any serine/threonine-phosphorylated targets, the result suggests that 14-3-3/Shc scaffolds can act as multivalent signaling nodes for the integration of both phosphoserine/threonine and phosphotyrosine pathways to regulate specific cellular responses. Thus, interaction of 14-3-3 with proteins via noncanonical binding sites of 14-3-3 should contribute to the diversity of its roles in a wide variety of biological pathways including membrane trafficking.

In addition, the propensity of the different 14-3-3 isoforms to form homo- or hetero-dimers may confer additional specificity to the scaffolding roles. Those regions of the 14-3-3 protein which vary between the isoforms are primarily located on the surface of the protein. Therefore, the specificity of interaction of 14-3-3 isoforms with diverse target proteins may involve the outer surface of the protein. For instance, C-termini of 14-3-3 proteins are most divergent and hence most likely to contain isoform-specific structural determinants (Williams et al., 2011). Identification of more protein complexes whose assembly requires 143-3 is necessary to gain more mechanistic insights into the scaffolding function of 14-3-3.

\subsubsection{Clamping}

Another mechanism by which 14-3-3 proteins are thought to exert their effect on their targets are conformational 'clamping'. Clamping can occur when a 14-3-3 dimer binds two sites on the same target protein. A synthetic phosphopeptide with two tandem 14-3-3 consensus motifs binds over 30 -fold more tightly than the same peptide containing only a 
single motif (Yaffe et al., 1997). A number of 14-3-3-binding proteins, including Raf-1 (Muslin et al., 1996), AANAT (Ganguly et al., 2005), ADAM22 (Godde et al., 2006), tyrosine hydroxylase (Toska et al., 2002), and Ndel1 (Johnson et al., 2010), contain two phosphorylated sites that are implicated in 14-3-3 binding, and are separated by polypeptides of various lengths. It has been postulated that one site called the 'gatekeeper' is indispensable for a stable 14-3-3 interaction, whereas a second site 'enhances' the interaction, but has too weak an affinity to bind 14-3-3 alone (Yaffe, 2002). In the case of AANAT, the gatekeeper residue is phosphorylated threonine ${ }^{31}$. Binding of the gatekeeper leads to binding of a second low-affinity site, in this case phosphorylated serine ${ }^{205}$, which reflects both the intrinsic affinity of that site and the 'high local concentration induced by its proximity' (Ganguly et al., 2005; Yaffe, 2002). This dual-site binding of AANAT to 14-3-3 provides optimal conformation of the enzyme for high-affinity binding of the substrate arylalkylamine.

14-3-3 clamping can also occur when a 14-3-3 dimer binds two neighboring target proteins. 14-3-3 proteins activate the plant plasma membrane $\mathrm{H}(+)$-ATPase (PMA2) by binding to its C-terminal autoinhibitory domain. This interaction requires phosphorylation of a C-terminal mode III recognition motif as well as an adjacent span of 52 amino acids. X-ray diffraction studies using crystals of 14-3-3 in complex with the entire binding motif of the PMA2 have shown that each 14-3-3 dimer simultaneously binds to two $\mathrm{H}^{+}$-ATPase molecules. The 3D reconstruction of the purified $\mathrm{H}(+)$-ATPase/14-3-3 complex demonstrated a hexagonal structure consisting of six PMA2 subunits and six 14-3-3 proteins (Ottmann et al., 2007). Thus, a rigid 14-3-3 'clamps' stabilize the dodecameric compex in the active conformation where C-terminal auto-inhibitory domain of PMA would be displaced.

With regards to membrane protein trafficking, clamping activity of 14-3-3 proteins has been much less well understood. This is largely due to the, as yet, small number of studies in this research area and the lack of high-resolution structure of the 14-3-3/target membrane protein complex, which are also true for 'masking' and 'scaffolding' mechanisms. However, the ability of 14-3-3 to change conformation of target proteins suggests the possibility that such conformational change will lead to a new interaction of the target with proteins that are involved in protein trafficking. This way 14-3-3 might indirectly exert the scaffolding function that eventually modulates the protein sorting of the client protein. Alternatively, instead of direct 'masking' of RXR motif by 14-3-3, 14-3-3 binding might force the target protein into the conformation where the RXR motif will be occluded. The RXR motif was previously found to have its functional 'zoning' in relation to the transmembrane region in the context of a reporter CD4 protein (Shikano \& Li, 2003). This notion was based on the observation that the ER localization activity of RXR motif was lost when it was positioned proximal to the transmembrane region of CD4. This zoning model was supported by the later study on the gamma-aminobutyric acid type B (GABAB) receptor (Gassmann et al., 2005). An RXR motif (RSRR) is responsible for the ER retrieval of the GABAB1 subunits that were not properly assembled with GABAB2 subunits. It had been thought that coiled-coil interaction of the GABAB1 with GABAB2 will shield RSRR signal on GABAB1. However, closer positioning of RSRR signal to the membrane region drastically reduced its effectiveness and also functional ectopic RSRR signals in GABAB1 were efficiently inactivated by the GABAB2 subunit in the absence of coiled-coil dimerization (Gassmann et al., 2005). These results were consistent with a model in which removal of RSRR from its functionally active zone, rather than its direct shielding by 
coiled-coil dimerization, triggers cell surface trafficking of GABAB receptors. Thus, it is interesting to speculate that clamping of two different 14-3-3 binding sites, either within the same target protein or in two neighboring proteins, might lead to the placement of RXR motifs in a non-functional zone such as membrane proximity and suppress ER localization of target membrane proteins.

\subsubsection{Other mechanisms by which 14-3-3s modulate membrane protein trafficking}

Modulation of membrane protein localization by 14-3-3s is not necessarily mediated by their binding to the cargo protein itself. It is not surprising that 14-3-3 binding to any cellular machinery proteins involved in biosynthetic pathways would affect their functions and thereby affect the sorting of the cargo protein.

The best characterized mechanism of this type involves the interaction of 14-3-3 with AS160, a Rab GTPase-activating protein (Rab-GAP). AS160 is an Akt substrate whose phosphorylation contributes to the recruitment of GLUT4 transporters to adipocyte plasma membrane in response to insulin (Watson \& Pessin, 2006). It maintains Rab proteins with which it associates in their inactive, GDP-bound states. Several evidences implicate Akt-mediated AS160 phosphorylation and the subsequent 14-3-3 binding in the recruitment of the GLUT4 glucose transporter to the cell surface of adipocytes (Ramm et al., 2006; Watson \& Pessin, 2006). Insulin stimulation leads to the recruitment of Akt to the plasma membrane where it gets activated and then phosphorylate AS160 at serine ${ }^{341}$ and threonine $e^{642}$. It is thought that the binding of 14-3-3 to AS160 inhibits its Rab-GAP activity toward substrate Rabs (Ishikura et al., 2007), which stabilizes them at GTP-bound active form and thereby facilitate the trafficking of cargo vesicles. Interestingly, insulin-dependent cell surface transport of GLUT4 is known to be primarily mediated by Akt isoform 2 (Akt2) but not Akt1 in adipocytes (Bae et al., 2003; Cho et al., 2001). A recent study by Gonzalez and McGraw demonstrated that upon insulin stimulation, Akt2 is able to remain associated with plasma membrane longer than Akt1 does and this leads to the Akt2-specific phosphorylation of AS160, which is necessary for GLUT4 trafficking (Gonzalez \& McGraw, 2009). It will be interesting to investigate whether and how this Akt isoform-specific phosphorylation of AS160 regulates 14-3-3 binding.

The surface expression of the epithelial sodium channel $(\mathrm{ENaC})$ seems to be regulated in a similar manner that involves AS160-14-3-3 interaction (Liang et al., 2010). Aldosterone stimulation of renal epithelial cell induces the expression of serum- and glucocorticoidinduced kinase (SGK1) that increases the cell surface expression of $\mathrm{ENaC}$ and $\mathrm{Na}$ absorption (Bhalla et al., 2006). Aldosterone also induces the expression of two 14-3-3 protein isoforms, $\beta$ and $\varepsilon$ (Liang et al., 2006). Liang et al. reported that SGK1, which is the downstream kinase of PI3K and shares with Akt the recognition motif of RXRXXS/T (Tessier \& Woodgett, 2006), phosphorylates AS160 upon aldosterone stimulation and this recruits the induced 14-3-3 isoforms (Liang et al., 2010), similar to the insulin-induced Akt phosphorylation of AS160. Inhibition of ENaC surface transport by expression of AS160 carrying mutations in SGK1 target sites suggests that 14-3-3 downregulates AS160 function to eventually promote surface transport of $\mathrm{ENaC}$ and augment $\mathrm{Na}$ absorption in response to aldosterone. 
Furthermore, 14-3-3 also controls the surface expression level of ENaC by regulating its degradation machinery. Ubiquitination of $\mathrm{ENaC}$ by ubiquitin-E3 protein ligase Nedd4-2 leads to an increased rate of protein degradation. The activation of SGK1 by aldosterone results in the phosphorylation of Nedd4-2 and recruitment of 14-3-3 proteins to Nedd4-2. This 14-3-3 binding inhibits the interaction of Nedd4-2 with $\mathrm{ENaC}$ and thereby suppresses the ubiquitin-dependent degradation of ENaC (Ichimura et al., 2005; Liang et al., 2006). This results in the longer stability of $\mathrm{ENaC}$ on the cell surface.

14-3-3s also bind to another transport machinery protein, phosphofurin acidic cluster sorting protein (PACS)-2 (Aslan et al., 2009). PACS-2 recognizes an acidic cluster in the cytoplasmic tail of TRPP2 cation channel and localize the channel in the ER through interaction with the COPI complex (Kottgen et al., 2005). The 14-3-3 binding to PACS-2 is dependent on the phosphorylation of PACS-2 by AKt, and this 14-3-3 binding was found to be required for the ER targeting of the PACS-2 substrate cargo protein TRPP2 (Aslan et al., 2009). How binding of PACS-2 to 14-3-3 and COPI cooperate to mediate cargo traffic remains to be determined.

Cell surface expression of membrane proteins could be also regulated by 14-3-3 through modulation of endocytic processes. Recent study demonstrates the interaction of 14-3-3 with transferrin receptor trafficking protein (TTP) (Chiba et al., 2009). TTP specifically promotes the internalization of transferrin receptor (TfR), but not other receptors such as epidermal growth factor receptor (EGFR) and low-density lipoprotein receptor (LDLR), through the clathrin-dependent pathway (Tosoni et al., 2005). 14-3-3 proteins directly bind to TTP in the Akt-dependent manner and this interaction was enhanced by oxidative stress (Chiba et al., 2009). Although the in vivo role of this 14-3-3 binding in TTP transport was not shown in this study, it suggests another possible mechanism where kinase signaling utilizes 14-3-3 as an effector molecule to control the cell surface density of proteins.

\section{Conclusion}

The requirement of phosphorylation for 14-3-3 binding confers 14-3-3 proteins a primary role in regulating protein-protein interactions that are under the control of specific kinases and phosphatases. Accordingly, 14-3-3 constitutes a key player which stands at a point of cross-talk between a plethora of vital biological processes including signaling, metabolism, cell cycle, and protein trafficking. Although available data from biochemical, structural, and bioinformatics studies have provided substantial amounts of information that characterize 14-3-3/client interaction, several fundamental questions regarding 14-3-3 protein biology remain to be addressed.

Although proteomics have revealed over 200 proteins forming complex with 14-3-3, the information regarding kinases and phosphatases that regulate these interactions are limited. The relevant kinase is not known for the majority of 14-3-3-binding proteins and the substantial overlap between the recognition sites of numerous basophilic serine/threonine kinases and 14-3-3 binding sites make their identification very difficult. Equally important but even less well studied are the phosphatases relevant for 14-3-3 binding. When and how the 14-3-3 proteins dissociate from the client proteins is very poorly understood. Does it require dephosphorylation of the 14-3-3 binding site by phosphatases? If so, how can the phosphatases do that when the phosphorylated serine/threonine of a target protein is buried in the amphipathic ligand-binding groove of 14-3-3? Alternatively, does some other 
signaling event facilitate the release of 14-3-3s from client proteins? In the context of protein trafficking, 14-3-3 is known to modulate sorting of the client proteins by various different mechanisms. In many of the cases where surface membrane transport is promoted by 14-3-3 binding, 14-3-3 seems to impinge on the early step of ER-to-Golgi trafficking. However, except for a very small number of studies (Godde et al., 2006; Okamoto \& Shikano, 2011), it is not understood if 14-3-3 proteins remain bound to the client all along the trip to the cell surface or dissociate in any particular step of the vesicular trafficking by phosphatase activity. These problems make us realize that we still do not know enough about the biology of kinases and phosphatases, especially the spatio-temporal regulation of their activities in different cellular compartments.

Another important question that has been long discussed but not fully addressed is whether and how 14-3-3 isoforms play specific roles. The complete sequence conservation in the observed ligand-binding regions of 14-3-3 would support the hypothesis that there may be little isoform specificity in the interaction between 14-3-3 and client proteins; therefore isoform-specific function of 14-3-3 may result either from subcellular localization (Paul et al., 2005; van Hemert et al., 2004) or transcriptional regulation (Liang et al., 2006) of particular isotypes rather than from inherent differences in their ability to bind to particular ligands. However, several findings (Dubois et al., 1997; Gu \& Du, 1998; Ichimura et al., 1995) suggest that additional interactions may occur on the outer surface of 14-3-3. This may confer isoform specificity, since residues that are variable between 14-3-3 isoforms are located on the surface of the protein. It is also conceivable that due to the common occurrence of two 14-3-3 binding sites within the target protein, the synergy between the two may also lead to isoform preference of interaction. Studies have shown that 14-3-3 isoforms form heterodimers in vivo (Alvarez et al., 2003; Liang et al., 2008). The isoform-specific interaction with client proteins may become most relevant in a 'scaffolding' model, where a hetero-dimer consisting of different isoforms would bind to two separate targets via each isoform. Thus, it is likely that its propensity to form homo- and various heterodimeric combinations is crucial for the specificity of 14-3-3 isoform functions. Many apparent conclusions of 14-3-3 function within particular cell types are based on observations of a single isoform, and comparative data among isoforms are still limited. More analysis of the exact combinations of homo- and hetero-dimers of 14-3-3 isoforms that are present within cell compartments and that are involved in interactions with particular proteins will be important.

\section{References}

Alvarez, D., Callejo, M., Shoucri, R., Boyer, L., Price, G.B. \& Zannis-Hadjopoulos, M. (2003) Analysis of the cruciform binding activity of recombinant 14-3-3zeta-MBP fusion protein, its heterodimerization profile with endogenous 14-3-3 isoforms, and effect on mammalian DNA replication in vitro. Biochemistry, 42, 7205-7215.

Aslan, J.E., You, H., Williamson, D.M., Endig, J., Youker, R.T., Thomas, L., Shu, H., Du, Y., Milewski, R.L., Brush, M.H., Possemato, A., Sprott, K., Fu, H., Greis, K.D., Runckel, D.N., Vogel, A. \& Thomas, G. (2009) Akt and 14-3-3 control a PACS-2 homeostatic switch that integrates membrane traffic with TRAIL-induced apoptosis. Mol Cell, 34, 497-509.

Bae, S.S., Cho, H., Mu, J. \& Birnbaum, M.J. (2003) Isoform-specific regulation of insulindependent glucose uptake by Akt/protein kinase B. J Biol Chem, 278, 49530-49536. 
Barry, E.F., Felquer, F.A., Powell, J.A., Biggs, L., Stomski, F.C., Urbani, A., Ramshaw, H., Hoffmann, P., Wilce, M.C., Grimbaldeston, M.A., Lopez, A.F. \& Guthridge, M.A. (2009) 14-3-3:Shc scaffolds integrate phosphoserine and phosphotyrosine signaling to regulate phosphatidylinositol 3-kinase activation and cell survival. J Biol Chem, 284, 12080-12090.

Benzinger, A., Popowicz, G.M., Joy, J.K., Majumdar, S., Holak, T.A. \& Hermeking, H. (2005) The crystal structure of the non-liganded 14-3-3sigma protein: insights into determinants of isoform specific ligand binding and dimerization. Cell Res, 15, 219227.

Bhalla, V., Soundararajan, R., Pao, A.C., Li, H. \& Pearce, D. (2006) Disinhibitory pathways for control of sodium transport: regulation of ENaC by SGK1 and GILZ. Am J Physiol Renal Physiol, 291, F714-721.

Bodnar, R.J., Gu, M., Li, Z., Englund, G.D. \& Du, X. (1999) The cytoplasmic domain of the platelet glycoprotein Ibalpha is phosphorylated at serine 609. J Biol Chem, 274, 33474-33479.

Bradshaw, J.M. \& Waksman, G. (2002) Molecular recognition by SH2 domains. Adv Protein Chem, 61, 161-210.

Braselmann, S. \& McCormick, F. (1995) Bcr and Raf form a complex in vivo via 14-3-3 proteins. Embo J, 14, 4839-4848.

Brunet, A., Bonni, A., Zigmond, M.J., Lin, M.Z., Juo, P., Hu, L.S., Anderson, M.J., Arden, K.C., Blenis, J. \& Greenberg, M.E. (1999) Akt promotes cell survival by phosphorylating and inhibiting a Forkhead transcription factor. Cell, 96, 857-868.

Chang, I.F., Curran, A., Woolsey, R., Quilici, D., Cushman, J.C., Mittler, R., Harmon, A. \& Harper, J.F. (2009) Proteomic profiling of tandem affinity purified 14-3-3 protein complexes in Arabidopsis thaliana. Proteomics, 9, 2967-2985.

Chen, B.S. \& Roche, K.W. (2009) Growth factor-dependent trafficking of cerebellar NMDA receptors via protein kinase B/Akt phosphorylation of NR2C. Neuron, 62, 471-478.

Chiba, S., Tokuhara, M., Morita, E.H. \& Abe, S. (2009) TTP at Ser245 phosphorylation by AKT is required for binding to 14-3-3. J Biochem, 145, 403-409.

Cho, H., Mu, J., Kim, J.K., Thorvaldsen, J.L., Chu, Q., Crenshaw, E.B., 3rd, Kaestner, K.H., Bartolomei, M.S., Shulman, G.I. \& Birnbaum, M.J. (2001) Insulin resistance and a diabetes mellitus-like syndrome in mice lacking the protein kinase Akt2 (PKB beta). Science, 292, 1728-1731.

Chung, H.J., Huang, Y.H., Lau, L.F. \& Huganir, R.L. (2004) Regulation of the NMDA receptor complex and trafficking by activity-dependent phosphorylation of the NR2B subunit PDZ ligand. J Neurosci, 24, 10248-10259.

Chung, J.J., Okamoto, Y., Coblitz, B., Li, M., Qiu, Y. \& Shikano, S. (2009) PI3K/Akt signalling-mediated protein surface expression sensed by 14-3-3 interacting motif. Febs J, 276, 5547-5558.

Coblitz, B., Shikano, S., Wu, M., Gabelli, S.B., Cockrell, L.M., Spieker, M., Hanyu, Y., Fu, H., Amzel, L.M. \& Li, M. (2005) C-terminal recognition by 14-3-3 proteins for surface expression of membrane receptors. J Biol Chem, 280, 36263-36272.

Cull-Candy, S.G. \& Leszkiewicz, D.N. (2004) Role of distinct NMDA receptor subtypes at central synapses. Sci STKE, 2004, re16. 
Datta, S.R., Dudek, H., Tao, X., Masters, S., Fu, H., Gotoh, Y. \& Greenberg, M.E. (1997) Akt phosphorylation of BAD couples survival signals to the cell-intrinsic death machinery. Cell, 91, 231-241.

Dougherty, M.K. \& Morrison, D.K. (2004) Unlocking the code of 14-3-3. J Cell Sci, 117, 18751884.

Drake, M.T., Shenoy, S.K. \& Lefkowitz, R.J. (2006) Trafficking of G protein-coupled receptors. Circ Res, 99, 570-582.

Dubois, T., Rommel, C., Howell, S., Steinhussen, U., Soneji, Y., Morrice, N., Moelling, K. \& Aitken, A. (1997) 14-3-3 is phosphorylated by casein kinase I on residue 233. Phosphorylation at this site in vivo regulates Raf/14-3-3 interaction. J Biol Chem, 272, 28882-28888.

Durocher, D., Taylor, I.A., Sarbassova, D., Haire, L.F., Westcott, S.L., Jackson, S.P., Smerdon, S.J. \& Yaffe, M.B. (2000) The molecular basis of FHA domain:phosphopeptide binding specificity and implications for phospho-dependent signaling mechanisms. Mol Cell, 6, 1169-1182.

Farzan, M., Choe, H., Martin, K., Marcon, L., Hofmann, W., Karlsson, G., Sun, Y., Barrett, P., Marchand, N., Sullivan, N., Gerard, N., Gerard, C. \& Sodroski, J. (1997) Two orphan seven-transmembrane segment receptors which are expressed in CD4positive cells support simian immunodeficiency virus infection. J Exp Med, 186, 405411.

Fujita, N., Sato, S. \& Tsuruo, T. (2003) Phosphorylation of p27Kip1 at threonine 198 by p90 ribosomal protein S6 kinases promotes its binding to 14-3-3 and cytoplasmic localization. J Biol Chem, 278, 49254-49260.

Ganguly, S., Weller, J.L., Ho, A., Chemineau, P., Malpaux, B. \& Klein, D.C. (2005) Melatonin synthesis: 14-3-3-dependent activation and inhibition of arylalkylamine Nacetyltransferase mediated by phosphoserine-205. Proc Natl Acad Sci U S A, 102, 1222-1227.

Gardino, A.K., Smerdon, S.J. \& Yaffe, M.B. (2006) Structural determinants of 14-3-3 binding specificities and regulation of subcellular localization of 14-3-3-ligand complexes: a comparison of the X-ray crystal structures of all human 14-3-3 isoforms. Semin Cancer Biol, 16, 173-182.

Gassmann, M., Haller, C., Stoll, Y., Aziz, S.A., Biermann, B., Mosbacher, J., Kaupmann, K. \& Bettler, B. (2005) The RXR-type endoplasmic reticulum-retention/retrieval signal of GABAB1 requires distant spacing from the membrane to function. Mol Pharmacol, $68,137-144$.

Godde, N.J., D'Abaco, G.M., Paradiso, L. \& Novak, U. (2006) Efficient ADAM22 surface expression is mediated by phosphorylation-dependent interaction with 14-3-3 protein family members. J Cell Sci, 119, 3296-3305.

Gonzalez, E. \& McGraw, T.E. (2009) Insulin-modulated Akt subcellular localization determines Akt isoform-specific signaling. Proc Natl Acad Sci U S A, 106, 7004-7009.

$\mathrm{Gu}, \mathrm{M} . \& \mathrm{Du}, \mathrm{X}$. (1998) A novel ligand-binding site in the zeta-form 14-3-3 protein recognizing the platelet glycoprotein Ibalpha and distinct from the c-Raf-binding site. J Biol Chem, 273, 33465-33471.

Heusser, K., Yuan, H., Neagoe, I., Tarasov, A.I., Ashcroft, F.M. \& Schwappach, B. (2006) Scavenging of 14-3-3 proteins reveals their involvement in the cell-surface transport of ATP-sensitive K+ channels. J Cell Sci, 119, 4353-4363. 
Horak, M. \& Wenthold, R.J. (2009) Different roles of C-terminal cassettes in the trafficking of full-length NR1 subunits to the cell surface. J Biol Chem, 284, 9683-9691.

Ichimura, T., Uchiyama, J., Kunihiro, O., Ito, M., Horigome, T., Omata, S., Shinkai, F., Kaji, H. \& Isobe, T. (1995) Identification of the site of interaction of the 14-3-3 protein with phosphorylated tryptophan hydroxylase. J Biol Chem, 270, 28515-28518.

Ichimura, T., Wakamiya-Tsuruta, A., Itagaki, C., Taoka, M., Hayano, T., Natsume, T. \& Isobe, T. (2002) Phosphorylation-dependent interaction of kinesin light chain 2 and the 14-3-3 protein. Biochemistry, 41, 5566-5572.

Ichimura, T., Yamamura, H., Sasamoto, K., Tominaga, Y., Taoka, M., Kakiuchi, K., Shinkawa, T., Takahashi, N., Shimada, S. \& Isobe, T. (2005) 14-3-3 proteins modulate the expression of epithelial $\mathrm{Na}+$ channels by phosphorylation-dependent interaction with Nedd4-2 ubiquitin ligase. J Biol Chem, 280, 13187-13194.

Ishikura, S., Bilan, P.J. \& Klip, A. (2007) Rabs 8A and 14 are targets of the insulin-regulated Rab-GAP AS160 regulating GLUT4 traffic in muscle cells. Biochem Biophys Res Commun, 353, 1074-1079.

Jackson, M.R., Nilsson, T. \& Peterson, P.A. (1990) Identification of a consensus motif for retention of transmembrane proteins in the endoplasmic reticulum. Embo J, 9, 31533162.

Jackson, M.R., Nilsson, T. \& Peterson, P.A. (1993) Retrieval of transmembrane proteins to the endoplasmic reticulum. J Cell Biol, 121, 317-333.

Johnson, C., Crowther, S., Stafford, M., Campbell, D.G., Toth, R. \& Mackintosh, C. (2010) Bioinformatic and experimental survey of 14-3-3 binding sites. Biochem J, 427, 69-78.

Kakiuchi, K., Yamauchi, Y., Taoka, M., Iwago, M., Fujita, T., Ito, T., Song, S.Y., Sakai, A., Isobe, T. \& Ichimura, T. (2007) Proteomic Analysis of in Vivo 14-3-3 Interactions in the Yeast Saccharomyces cerevisiae. Biochemistry, 46, 7781-7792.

Khalil, H., Brunet, A. \& Thibodeau, J. (2005) A three-amino-acid-long HLA-DRbeta cytoplasmic tail is sufficient to overcome ER retention of invariant-chain p35. J Cell Sci, 118, 4679-4687.

Kino, T., Souvatzoglou, E., De Martino, M.U., Tsopanomihalu, M., Wan, Y. \& Chrousos, G.P. (2003) Protein 14-3-3sigma interacts with and favors cytoplasmic subcellular localization of the glucocorticoid receptor, acting as a negative regulator of the glucocorticoid signaling pathway. J Biol Chem, 278, 25651-25656.

Kobe, B., Kampmann, T., Forwood, J.K., Listwan, P. \& Brinkworth, R.I. (2005) Substrate specificity of protein kinases and computational prediction of substrates. Biochim Biophys Acta, 1754, 200-209.

Kottgen, M., Benzing, T., Simmen, T., Tauber, R., Buchholz, B., Feliciangeli, S., Huber, T.B., Schermer, B., Kramer-Zucker, A., Hopker, K., Simmen, K.C., Tschucke, C.C., Sandford, R., Kim, E., Thomas, G. \& Walz, G. (2005) Trafficking of TRPP2 by PACS proteins represents a novel mechanism of ion channel regulation. Embo J, 24, 705716.

Kumagai, A. \& Dunphy, W.G. (1999) Binding of 14-3-3 proteins and nuclear export control the intracellular localization of the mitotic inducer Cdc25. Genes Dev, 13, 1067-1072.

Kuwana, T., Peterson, P.A. \& Karlsson, L. (1998) Exit of major histocompatibility complex class II-invariant chain p35 complexes from the endoplasmic reticulum is modulated by phosphorylation. Proc Natl Acad Sci U S A, 95, 1056-1061. 
Liang, X., Butterworth, M.B., Peters, K.W. \& Frizzell, R.A. (2010) AS160 modulates aldosterone-stimulated epithelial sodium channel forward trafficking. Mol Biol Cell, 21, 2024-2033.

Liang, X., Butterworth, M.B., Peters, K.W., Walker, W.H. \& Frizzell, R.A. (2008) An obligatory heterodimer of 14-3-3beta and 14-3-3epsilon is required for aldosterone regulation of the epithelial sodium channel. J Biol Chem, 283, 27418-27425.

Liang, X., Peters, K.W., Butterworth, M.B. \& Frizzell, R.A. (2006) 14-3-3 isoforms are induced by aldosterone and participate in its regulation of epithelial sodium channels. J Biol Chem, 281, 16323-16332.

Lowery, D.M., Lim, D. \& Yaffe, M.B. (2005) Structure and function of Polo-like kinases. Oncogene, 24, 248-259.

Mackintosh, C. (2004) Dynamic interactions between 14-3-3 proteins and phosphoproteins regulate diverse cellular processes. Biochem J, 381, 329-342.

Manke, I.A., Lowery, D.M., Nguyen, A. \& Yaffe, M.B. (2003) BRCT repeats as phosphopeptide-binding modules involved in protein targeting. Science, 302, 636639.

Mant, A., Elliott, D., Eyers, P.A. \& O'Kelly, I.M. (2011) Protein kinase A is central for forward transport of two-pore domain potassium channels $\mathrm{K}(2 \mathrm{P}) 3.1$ and $\mathrm{K}(2 \mathrm{P}) 9.1$. J Biol Chem, 286, 14110-14119.

Meek, S.E., Lane, W.S. \& Piwnica-Worms, H. (2004) Comprehensive proteomic analysis of interphase and mitotic 14-3-3-binding proteins. J Biol Chem, 279, 32046-32054.

Michelsen, K., Schmid, V., Metz, J., Heusser, K., Liebel, U., Schwede, T., Spang, A. \& Schwappach, B. (2007) Novel cargo-binding site in the beta and delta subunits of coatomer. J Cell Biol, 179, 209-217.

Michelsen, K., Yuan, H. \& Schwappach, B. (2005) Hide and run. Arginine-based endoplasmic-reticulum-sorting motifs in the assembly of heteromultimeric membrane proteins. EMBO Rep, 6, 717-722.

Moore, B.W. \& Perez, V.J. (1967) Specific acidic proteins of the nervous system,. In: Physiological and Biochemical Aspects of Nervous Integration,, 343-359.

Mrowiec, T. \& Schwappach, B. (2006) 14-3-3 proteins in membrane protein transport. Biol Chem, 387, 1227-1236.

Munday, A.D., Berndt, M.C. \& Mitchell, C.A. (2000) Phosphoinositide 3-kinase forms a complex with platelet membrane glycoprotein Ib-IX-V complex and 14-3-3zeta. Blood, 96, 577-584.

Muslin, A.J., Tanner, J.W., Allen, P.M. \& Shaw, A.S. (1996) Interaction of 14-3-3 with signaling proteins is mediated by the recognition of phosphoserine. Cell, 84, 889897.

Nakamura, T., Hayashi, T., Mimori-Kiyosue, Y., Sakaue, F., Matsuura, K., Iemura, S.I., Natsume, T. \& Akiyama, T. (2010) The PX-RICS/14-3-3\{zeta\}/\{theta\} complex couples $\mathrm{N}$-cadherin/\{beta\}-catenin with dynein/dynactin to mediate its export from the endoplasmic reticulum. J Biol Chem, 285, 16145-16154.

O'Kelly, I., Butler, M.H., Zilberberg, N. \& Goldstein, S.A. (2002) Forward transport. 14-3-3 binding overcomes retention in endoplasmic reticulum by dibasic signals. Cell, 111, 577-588. 
Obsil, T., Ghirlando, R., Klein, D.C., Ganguly, S. \& Dyda, F. (2001) Crystal structure of the 14-3-3zeta:serotonin N-acetyltransferase complex. a role for scaffolding in enzyme regulation. Cell, 105, 257-267.

Okamoto, Y. \& Shikano, S. (2011) Phosphorylation-dependent C-terminal binding of 14-3-3 proteins promotes cell surface expression of HIV co-receptor GPR15. J Biol Chem, 286.

Ottmann, C., Marco, S., Jaspert, N., Marcon, C., Schauer, N., Weyand, M., Vandermeeren, C., Duby, G., Boutry, M., Wittinghofer, A., Rigaud, J.L. \& Oecking, C. (2007) Structure of a 14-3-3 coordinated hexamer of the plant plasma membrane $\mathrm{H}+$-ATPase by combining X-ray crystallography and electron cryomicroscopy. Mol Cell, 25, 427440.

Park, D.J., Wallick, C.J., Martyn, K.D., Lau, A.F., Jin, C. \& Warn-Cramer, B.J. (2007) Akt phosphorylates Connexin43 on Ser373, a "mode-1" binding site for 14-3-3. Cell Commun Adhes, 14, 211-226.

Paul, A.L., Sehnke, P.C. \& Ferl, R.J. (2005) Isoform-specific subcellular localization among 14-3-3 proteins in Arabidopsis seems to be driven by client interactions. Mol Biol Cell, 16, 1735-1743.

Pearson, R.B. \& Kemp, B.E. (1991) Protein kinase phosphorylation site sequences and consensus specificity motifs: tabulations. Methods Enzymol, 200, 62-81.

Pnueli, L., Gutfinger, T., Hareven, D., Ben-Naim, O., Ron, N., Adir, N. \& Lifschitz, E. (2001) Tomato SP-interacting proteins define a conserved signaling system that regulates shoot architecture and flowering. Plant Cell, 13, 2687-2702.

Pozuelo Rubio, M., Geraghty, K.M., Wong, B.H., Wood, N.T., Campbell, D.G., Morrice, N. \& Mackintosh, C. (2004) 14-3-3-affinity purification of over 200 human phosphoproteins reveals new links to regulation of cellular metabolism, proliferation and trafficking. Biochem J, 379, 395-408.

Ramm, G., Larance, M., Guilhaus, M. \& James, D.E. (2006) A role for 14-3-3 in insulinstimulated GLUT4 translocation through its interaction with the RabGAP AS160. J Biol Chem, 281, 29174-29180.

Rittinger, K., Budman, J., Xu, J., Volinia, S., Cantley, L.C., Smerdon, S.J., Gamblin, S.J. \& Yaffe, M.B. (1999) Structural analysis of 14-3-3 phosphopeptide complexes identifies a dual role for the nuclear export signal of 14-3-3 in ligand binding. Mol Cell, 4, 153-166.

Rong, J., Li, S., Sheng, G., Wu, M., Coblitz, B., Li, M., Fu, H. \& Li, X.J. (2007) 14-3-3 protein interacts with Huntingtin-associated protein 1 and regulates its trafficking. J Biol Chem, 282, 4748-4756.

Rosenberg, M.M., Yang, F., Giovanni, M., Mohn, J.L., Temburni, M.K. \& Jacob, M.H. (2008) Adenomatous polyposis coli plays a key role, in vivo, in coordinating assembly of the neuronal nicotinic postsynaptic complex. Mol Cell Neurosci, 38, 138-152.

Salvi, M., Sarno, S., Cesaro, L., Nakamura, H. \& Pinna, L.A. (2009) Extraordinary pleiotropy of protein kinase CK2 revealed by weblogo phosphoproteome analysis. Biochim Biophys Acta, 1793, 847-859.

Seimiya, H., Sawada, H., Muramatsu, Y., Shimizu, M., Ohko, K., Yamane, K. \& Tsuruo, T. (2000) Involvement of 14-3-3 proteins in nuclear localization of telomerase. Embo J, $19,2652-2661$. 
Setou, M., Nakagawa, T., Seog, D.H. \& Hirokawa, N. (2000) Kinesin superfamily motor protein KIF17 and mLin-10 in NMDA receptor-containing vesicle transport. Science, $288,1796-1802$.

Shikano, S., Coblitz, B., Sun, H. \& Li, M. (2005) Genetic isolation of transport signals directing cell surface expression. Nat Cell Biol, 7, 985-992.

Shikano, S. \& Li, M. (2003) Membrane receptor trafficking: evidence of proximal and distal zones conferred by two independent endoplasmic reticulum localization signals. Proc Natl Acad Sci U S A, 100, 5783-5788.

Sliva, D., Gu, M., Zhu, Y.X., Chen, J., Tsai, S., Du, X. \& Yang, Y.C. (2000) 14-3-3zeta interacts with the alpha-chain of human interleukin 9 receptor. Biochem J, $345 \mathrm{Pt}$ 3, 741-747.

Tessier, M. \& Woodgett, J.R. (2006) Serum and glucocorticoid-regulated protein kinases: variations on a theme. J Cell Biochem, 98, 1391-1407.

Tobin, A.B. (2008) G-protein-coupled receptor phosphorylation: where, when and by whom. Br J Pharmacol, 153 Suppl 1, S167-176.

Toska, K., Kleppe, R., Armstrong, C.G., Morrice, N.A., Cohen, P. \& Haavik, J. (2002) Regulation of tyrosine hydroxylase by stress-activated protein kinases. J Neurochem, 83, 775-783.

Tosoni, D., Puri, C., Confalonieri, S., Salcini, A.E., De Camilli, P., Tacchetti, C. \& Di Fiore, P.P. (2005) TTP specifically regulates the internalization of the transferrin receptor. Cell, 123, 875-888.

Tzivion, G. \& Avruch, J. (2002) 14-3-3 proteins: active cofactors in cellular regulation by serine/threonine phosphorylation. J Biol Chem, 277, 3061-3064.

Ubersax, J.A. \& Ferrell, J.E., Jr. (2007) Mechanisms of specificity in protein phosphorylation. Nat Rev Mol Cell Biol, 8, 530-541.

Van Der Hoeven, P.C., Van Der Wal, J.C., Ruurs, P., Van Dijk, M.C. \& Van Blitterswijk, J. (2000) 14-3-3 isotypes facilitate coupling of protein kinase C-zeta to Raf-1: negative regulation by 14-3-3 phosphorylation. Biochem J, 345 Pt 2, 297-306.

van Hemert, M.J., Niemantsverdriet, M., Schmidt, T., Backendorf, C. \& Spaink, H.P. (2004) Isoform-specific differences in rapid nucleocytoplasmic shuttling cause distinct subcellular distributions of 14-3-3 sigma and 14-3-3 zeta. J Cell Sci, 117, 1411-1420.

van Hemert, M.J., Steensma, H.Y. \& van Heusden, G.P. (2001) 14-3-3 proteins: key regulators of cell division, signalling and apoptosis. Bioessays, 23, 936-946.

Vincenz, C. \& Dixit, V.M. (1996) 14-3-3 proteins associate with A20 in an isoform-specific manner and function both as chaperone and adapter molecules. J Biol Chem, 271, 20029-20034.

Watson, R.T. \& Pessin, J.E. (2006) Bridging the GAP between insulin signaling and GLUT4 translocation. Trends Biochem Sci, 31, 215-222.

Widen, C., Zilliacus, J., Gustafsson, J.A. \& Wikstrom, A.C. (2000) Glucocorticoid receptor interaction with 14-3-3 and Raf-1, a proposed mechanism for cross-talk of two signal transduction pathways. J Biol Chem, 275, 39296-39301.

Wilker, E.W., Grant, R.A., Artim, S.C. \& Yaffe, M.B. (2005) A structural basis for 14-3-3sigma functional specificity. J Biol Chem, 280, 18891-18898.

Williams, D.M., Ecroyd, H., Goodwin, K.L., Dai, H., Fu, H., Woodcock, J.M., Zhang, L. \& Carver, J.A. (2011) NMR spectroscopy of 14-3-3zeta reveals a flexible C-terminal extension: differentiation of the chaperone and phosphoserine-binding activities of 14-3-3zeta. Biochem J, 437, 493-503. 
Wurtele, M., Jelich-Ottmann, C., Wittinghofer, A. \& Oecking, C. (2003) Structural view of a fungal toxin acting on a 14-3-3 regulatory complex. Embo J, 22, 987-994.

Yaffe, M.B. (2002) How do 14-3-3 proteins work?-- Gatekeeper phosphorylation and the molecular anvil hypothesis. FEBS Lett, 513, 53-57.

Yaffe, M.B. \& Elia, A.E. (2001) Phosphoserine/threonine-binding domains. Curr Opin Cell Biol, 13, 131-138.

Yaffe, M.B., Rittinger, K., Volinia, S., Caron, P.R., Aitken, A., Leffers, H., Gamblin, S.J., Smerdon, S.J. \& Cantley, L.C. (1997) The structural basis for 14-3-3:phosphopeptide binding specificity. Cell, 91, 961-971.

Yano, M., Mori, S., Niwa, Y., Inoue, M. \& Kido, H. (1997) Intrinsic nucleoside diphosphate kinase-like activity as a novel function of 14-3-3 proteins. FEBS Lett, 419, 244-248.

Yano, M., Nakamuta, S., Wu, X., Okumura, Y. \& Kido, H. (2006) A novel function of 14-3-3 protein: 14-3-3zeta is a heat-shock-related molecular chaperone that dissolves thermal-aggregated proteins. Mol Biol Cell, 17, 4769-4779.

Yuan, H., Michelsen, K. \& Schwappach, B. (2003) 14-3-3 dimers probe the assembly status of multimeric membrane proteins. Curr Biol, 13, 638-646.

Zerangue, N., Schwappach, B., Jan, Y.N. \& Jan, L.Y. (1999) A new ER trafficking signal regulates the subunit stoichiometry of plasma membrane K(ATP) channels. Neuron, 22, 537-548.

Zha, J., Harada, H., Osipov, K., Jockel, J., Waksman, G. \& Korsmeyer, S.J. (1997) BH3 domain of $\mathrm{BAD}$ is required for heterodimerization with BCL-XL and pro-apoptotic activity. J Biol Chem, 272, 24101-24104.

Zha, J., Harada, H., Yang, E., Jockel, J. \& Korsmeyer, S.J. (1996) Serine phosphorylation of death agonist $\mathrm{BAD}$ in response to survival factor results in binding to 14-3-3 not BCL-X(L). Cell, 87, 619-628. 


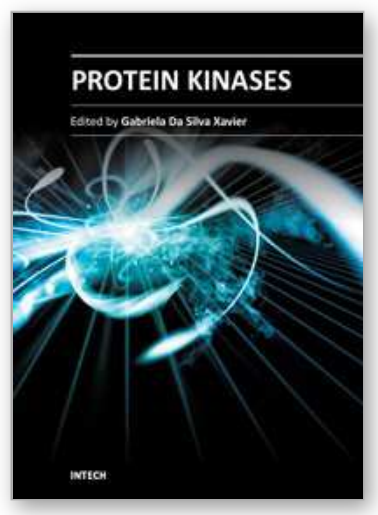

\author{
Protein Kinases \\ Edited by Dr. Gabriela Da Silva Xavier
}

ISBN 978-953-51-0640-1

Hard cover, 484 pages

Publisher InTech

Published online 05, June, 2012

Published in print edition June, 2012

Proteins are the work horses of the cell. As regulators of protein function, protein kinases are involved in the control of cellular functions via intricate signalling pathways, allowing for fine tuning of physiological functions. This book is a collaborative effort, with contribution from experts in their respective fields, reflecting the spirit of collaboration - across disciplines and borders - that exists in modern science. Here, we review the existing literature and, on occasions, provide novel data on the function of protein kinases in various systems. We also discuss the implications of these findings in the context of disease, treatment, and drug development.

\title{
How to reference
}

In order to correctly reference this scholarly work, feel free to copy and paste the following:

Yukari Okamoto and Sojin Shikano (2012). Phosphorylation-Regulated Cell Surface Expression of Membrane Proteins, Protein Kinases, Dr. Gabriela Da Silva Xavier (Ed.), ISBN: 978-953-51-0640-1, InTech, Available from: http://www.intechopen.com/books/protein-kinases/phosphorylation-regulated-cell-surface-expression-ofmembrane-proteins

\section{INTECH}

open science | open minds

\section{InTech Europe}

University Campus STeP Ri

Slavka Krautzeka 83/A

51000 Rijeka, Croatia

Phone: +385 (51) 770447

Fax: +385 (51) 686166

www.intechopen.com

\section{InTech China}

Unit 405, Office Block, Hotel Equatorial Shanghai

No.65, Yan An Road (West), Shanghai, 200040, China

中国上海市延安西路65号上海国际贵都大饭店办公楼 405 单元

Phone: +86-21-62489820

Fax: +86-21-62489821 
(C) 2012 The Author(s). Licensee IntechOpen. This is an open access article distributed under the terms of the Creative Commons Attribution 3.0 License, which permits unrestricted use, distribution, and reproduction in any medium, provided the original work is properly cited. 